\title{
INTEGRAL FORMING OF TURBINE DRILL IMPELLER
}

\author{
Fang Chen ${ }^{1}$, Ramón Lorenzo-Gómez ${ }^{1}$, Kwadwo Ansong Asante ${ }^{1}$ \\ ${ }^{1} \mathrm{Xi}$ 'an Aeronautical Polytechnic Institute, Xi'an, China
}

\begin{abstract}
In order to reduce the cost of small batch production of turbodrill and improve the quality of blade processing, the integrated processing of turbodrill impeller is taken as the main research content. Firstly, the WZ-115 turbodrill impeller is used to process the turbodrill impeller. Secondly, the three-dimensional model of the blade output from ANSYS/BladeGen module is drawn by UG software. After obtaining the three-dimensional model, the processing module of UG software is used to design the processing technology, determine the processing steps and routes, and compile the processing program. The tool path of rough and finish machining is observed and modified by using simulated processing, and the amount of tool eaten at each stage is improved to generate the processing program. Finally, the impeller is measured by the coordinate measuring instrument, and the errors of the data are analyzed by UG software. The results show that the turbodrill impeller meets the requirements of processing accuracy, the surface profile meets the design requirements, the surface processing quality meets the expectations, and the turbodrill impeller has the ability of actual processing, which can effectively solve the problem of high cost in small batch production such as university test and enterprise research and development. It can be seen that the integral forming technology of turbo drill impeller can effectively solve the problem of long production cycle in the process of turbo drill development and test, and control it. At the same time, the cost can efficiently and quickly complete the processing of turbo drill, and can ensure the processing quality.
\end{abstract}

Keywords: Turbine Drilling Tool, Impeller Machining, UG, Error Analysis.

\section{Introduction}

With the deepening of exploration and development of oil and gas fields, the development of high pressure, high permeability and high yield oil and gas fields has entered the middle and late stages.

At present, the development goal of oil and gas fields is gradually shifting to low pressure, low permeability and low production fields. However, the exploration and development of such fields are difficult, and the cost of investment is increasing day by day. At the same time, the international crude oil price has entered a new round of sharp decline since June 2014. The price of crude oil has fallen from about $\$ 110$ a barrel to the lowest of $\$ 26$, a drop of more than $70 \%$. Increasing development costs and the sharp drop in crude oil prices have seriously affected the overall profits of oil extraction, refining and other industries. The oil industry is facing an unprecedented crisis.

Facing the increasing development cost and the crisis under the new international situation, the petroleum industry puts forward new requirements for the development of oil and gas fields, which include technological progress to meet the increasingly difficult drilling and reducing development costs to adapt to the new normal of low crude oil prices. Therefore, how to improve drilling technology, reduce drilling costs and increase oil recovery have become a major consideration in oil and gas field development.

Turbine drilling tools, as the main branch of down hole drilling tools, have unique working methods. They have obvious advantages in dealing with the problems of unconventional oil and gas field development and complex oil and gas field drilling and production. In the 1980s, down hole power drilling tools, with turbo drill and screw drilling tools as the main parts, were regarded as one of the three major technologies in the progress of petroleum engineering.

Compared with rotary drilling, turbo drill can increase the penetration rate by 3-5 times and save drilling cost by $20-30 \%$. Turbine drilling tools are characterized by high penetration rate, good borehole quality control, accurate borehole trajectory, safety, high speed and economy. Turbine drilling tools have been widely used in vertical, directional, cluster and sidetracking drilling operations in recent years, and the main drilling technical indicators have been improved.

Impeller is one of the core components of turbo drill, which includes stator impeller and rotor impeller. At present, the production of impeller mainly adopts precision casting or wire cutting. The former is prone to shrinkage and deformation during 
processing, and needs to open the mould. The cost of small batch production is high, which cannot meet the test needs of universities or scientific research institutions. The latter has complex technology and low product precision, which makes it difficult to guarantee the stiffness and strength of impeller.

\section{Literature Review}

The development of turbo drill types has mainly experienced changes from turbo drill, single-stage turbo drill, multi-stage turbo drill, to turbo drill with reducer and compound turbo drill [1].

In recent years, turbo drill has been widely used in vertical well, directional well, cluster well, sidetracking and other drilling operations, which makes the main technical indicators of drilling have been improved.

In order to meet the needs of modern drilling, turbo drill tends to develop in small diameter, high power, high speed and high life [2].

At the same time, it expands the application field of equipment, gradually adapts to and meets the needs of slim hole drilling and continuous pipe drilling [3].

In addition, it also has been applied in formation tolerance, exploration and other work.

For the purpose of NC machining of turbo drill impeller, Wang et al. put forward a comprehensive processing method based on UG software [4].

The impeller is measured by three coordinate measuring instruments. The error analysis of the data is carried out by UG software. The results show that the surface processing quality met the expectation [5].

Dashy et al. take the impeller of a turbocharged engine as an example to analyze the material selection and forming method of the impeller.

By analyzing and choosing the milling method to produce the impeller, the main processing procedures of the impeller are analyzed in detail, and a set of practical and convenient processing scheme is put forward. The NC program is simulated in VERICUT 7.2 and added in the machine tool.

The correctness of the processing scheme is verified by the work [6].

On the basis of the general theory of threedimensional flow in turbo machinery and the specific boundary problem of turbo drill impeller, Tao et al. establish the mathematical model of threedimensional flow calculation, deduce the flow function equation suitable for three-dimensional flow calculation in turbo machinery, and successfully apply the three-dimensional flow calculation flow function method to the numerical calculation of turbo drill cascade [7].

\section{Methodology}

\subsection{Processing method}

With the development of computer aided design, computer aided manufacturing technology and numerical control processing technology, various kinds of impellers and blades are also processed in multi-axis NC machining, which has become a commonly used method at home and abroad.

This technology has the characteristics of high processing accuracy, high speed, low King stress and good surface quality control. It is widely used in the production of large turbines such as steam turbines, aero-engines, hydro-turbines, and small impellers such as automotive wheel hoists.

This technology usually uses three-dimensional modeling software to model the impeller and blade of known blade profile, then compiles the processing program by computer, carries on the computer simulation processing, optimizes the processing route and the manufacturing process, and finally inputs the optimized processing program into the processing center through I/O port for processing.

Multi-axis NC machining technology can greatly improve production efficiency, improve processing accuracy and ensure processing quality.

However, due to the expensive purchase and maintenance costs of CNC machining centers, the technology has not been promoted in the turbo drill manufacturing industry.

However, when the turbo drill is tested and studied, a certain number of finished products are needed to meet the demand.

The traditional processing method is expensive in small batch production, and the production cycle is long, which is not conducive to the test.

Therefore, multi-axis NC machining technology is adopted to overcome the technological difficulties and realize the integral shaping of turbo drill impeller.

The optimized turbo drill impeller is modeled by the three-dimensional modeling software UG.

The processing module of the software is used to compile the processing program, simulate the processing by computer and optimize the program.

Finally, the whole processing of the impeller is completed by the machining center.

Using numerical control processing technology and multi-axis CNC machining center, the WZ-115 turbo drill impeller is processed in an integrated way.

The specific flow chart is shown in Figure 1 and the specific content is shown in Table 1. 
Table 1: Specific contents of processing processes

\begin{tabular}{|c|l|}
\hline $\begin{array}{c}\text { Serial } \\
\text { number }\end{array}$ & \multicolumn{1}{c|}{ Contents } \\
\hline 1 & $\begin{array}{l}\text { The blade profiles of WZ-115 turbo drill blades with different installation angles are imported } \\
\text { into UG, and the complete H-dimensional model of impeller is drawn by using UG. }\end{array}$ \\
\hline 2 & $\begin{array}{l}\text { The CNC processing module is used to compile and simulate the process of impeller integral } \\
\text { forming. The shortcomings and defects in the process are found. The program is optimized to } \\
\text { ensure the accuracy and economy of the program. }\end{array}$ \\
\hline 3 & $\begin{array}{l}\text { According to the operating system and its own characteristics of the existing machining center, } \\
\text { the program is processed to meet the processing requirements. }\end{array}$ \\
\hline 4 & $\begin{array}{l}\text { The post-processing program will be imported into the existing machining center to match the } \\
\text { special fixture which has been designed and processed in advance to complete the processing } \\
\text { task. }\end{array}$ \\
\hline
\end{tabular}

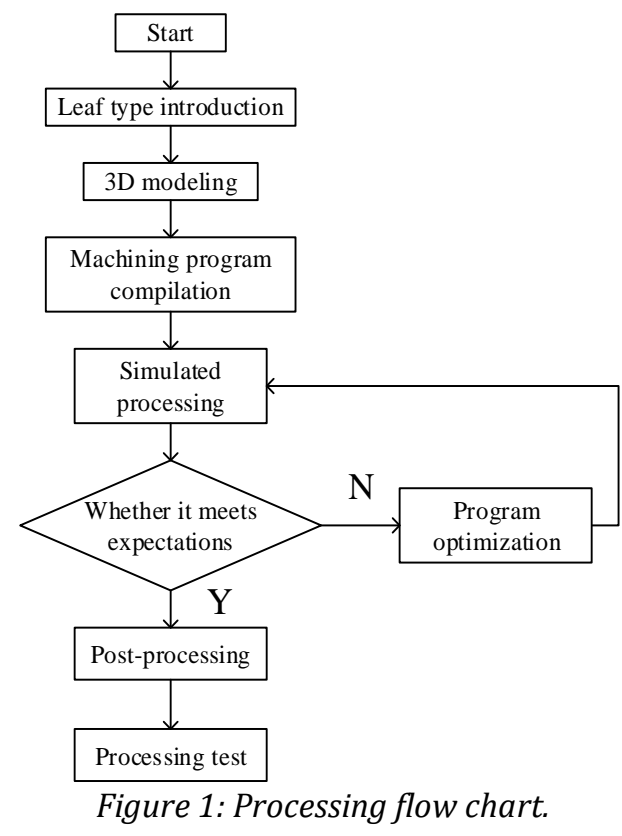

\subsection{Compilation of processing programs}

In view of the straight blade characteristics of turbo drill impeller, the "plane milling" processing command is selected after comparison. The characteristic of the command is that the feeding route is short, which can greatly reduce the overlap of repeated feeding and quickly remove the spare parts.
The material used in the processing test is aluminum alloy, and the cutting tool is made of several high-speed steel face milling cutters with a diameter of $5 \mathrm{~mm}$. In the process, the runner surface between the two blades is firstly removed, and then the single blade is processed. Processing pressure surface and suction surface are roughly and precisely processed to ensure processing accuracy and improve processing quality.

After completing the above settings, the tool path of a single blade is generated.

The bottom surface of the runner is an irregular surface, which needs to be processed separately. Otherwise, the surface roughness will be lower and the hydraulic performance of the blade will be affected.

When programming, the hidden danger caused by the small distance between two blades should be fully considered.

Because the area of the bottom surface of the runner is too small to use the surface as the control surface for "variable contour milling", the "cavity milling" command to take the projection of the runner surface contour on the XY plane is used as the "pruning boundary" in processing, to restrict the processing range and prevent interference.

The generated tool path is modified and optimized to smooth the tool path and avoid overcutting caused by sharp changes. The specific process is shown in Table 2.

Table 2: Specific processing program compilation process

\begin{tabular}{|c|l|}
\hline $\begin{array}{c}\text { Serial } \\
\text { number }\end{array}$ & \multicolumn{1}{|c|}{ Contents } \\
\hline 1 & $\begin{array}{l}\text { To create contour milling operation, the driving mode is "zone milling" and the direction of cutter } \\
\text { axis is + ZM axis. }\end{array}$ \\
\hline 2 & $\begin{array}{l}\text { The cutting area is designated as the bottom of the runner, and the "pruning boundary" is } \\
\text { designated as the projection curve of the runner surface. }\end{array}$ \\
\hline 3 & $\begin{array}{l}\text { Cutting parameters are set and reverse milling is adopted. The maximum step length is } 20 \% \text { of the } \\
\text { tool diameter. }\end{array}$ \\
\hline 4 & $\begin{array}{l}\text { Non-cutting parameters are set. The feed type is "insertion", and the length of linear extended tool } \\
\text { is 80\%. }\end{array}$ \\
\hline 5 & $\begin{array}{l}\text { The feed parameters are set, the cutting speed is } 250 \mathrm{~mm} / \mathrm{min} \text {, and the tool path is generated and } \\
\text { verified. }\end{array}$ \\
\hline
\end{tabular}




\section{Results and Discussion}

\subsection{Drawing of three-dimensional model}

Using UG software to open the IGES file output by Blade Gen module, a single channel model can be obtained. In this single channel model, the parameters of blade profile, flow channel and blade height are included, and the parameters of blade profile are expressed by a closed curve composed of four spine curves.

Turbine drill impeller is generally composed of three parts, which are base, blade and outer ring. When machining the impeller as a whole, because the overall size of the impeller is small, the machining position of the tool must be considered.

If the impeller has an outer ring, too small interspaces between blades makes the tool unable to process the normal surface.

Therefore, the outer ring of the traditional impeller must be deleted in the three-dimensional modeling.

Drawing the three-dimensional model of impeller is shown in Table 3.

Table 3: Drawing the specific content of threedimensional model of impeller

\begin{tabular}{|c|l|}
\hline $\begin{array}{c}\text { Serial } \\
\text { number }\end{array}$ & \multicolumn{1}{|c|}{ Contents } \\
\hline 1 & $\begin{array}{l}\text { The remaining features of IGES } \\
\text { output model are deleted, and only } \\
\text { four curves (suction surface curve, } \\
\text { pressure surface curve, tip semi- } \\
\text { circular arc, root semi-circular arc) } \\
\text { that constitute the profile of blade } \\
\text { are retained. }\end{array}$ \\
\hline 2 & $\begin{array}{l}\text { After the displacement, pruning and } \\
\text { perfection of the curve, the complete } \\
\text { profile curve is finally obtained. }\end{array}$ \\
\hline 3 & $\begin{array}{l}\text { In the three-dimensional modeling } \\
\text { interface of UG software, a single } \\
\text { blade model is obtained by } \\
\text { stretching the curve. }\end{array}$ \\
\hline 5 & $\begin{array}{l}\text { According to the relative position } \\
\text { relationship, the reference plane is } \\
\text { established at one end of the blade, } \\
\text { and the outline of the revolving } \\
\text { body is drawn. The impeller valley is } \\
\text { generated by scanning command. }\end{array}$ \\
\hline $\begin{array}{l}\text { Using array command, a complete } \\
\text { three-dimensional model of impeller } \\
\text { is obtained by arraying a single } \\
\text { blade. }\end{array}$ \\
\hline 5
\end{tabular}

Finally, a complete three-dimensional model of the impeller is obtained, as shown in Figure 2.

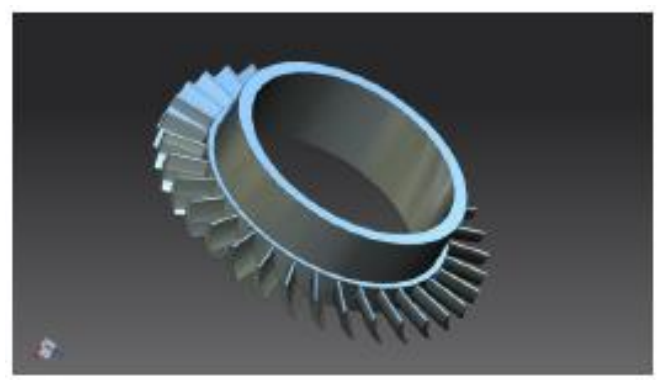

Figure 2: Three-dimensional impeller model.

\subsection{Analysis of processing technology}

The difficulties in the integral machining of turbo drill impeller lie in the integral diameter of impeller, the small size of single blade, the short distance between blades, the small cutting force that can be withstood, and the high probability of interference and tool bumping.

The outer diameter of the impeller is $\varphi 240$, the average circumferential distribution of 31 blades, the blade spacing is less than $15 \mathrm{~mm}$, the channel surface is narrow, and the processing is difficult.

According to the above issues, in order to improve the surface quality of the blade and prevent collision and interference in the process of machining, side milling method is adopted, which means that the side edge of cylindrical milling cutter with smaller diameter is used to milling blade surface. Since the impeller runner is too narrow, the blade head cannot be perpendicular to the blade back and the blade basin surface, so only cylindrical milling cutter can be used to complete the blade profile processing according to the blade crosssection shape.

Among the existing processing equipment, FEELER FMH-400 horizontal machining center can well meet the processing requirements. FANUC 31I $\mathrm{NC}$ operating system is also used in this type of processing. The power of the main motor is $7.5 \mathrm{KW}$, the travel of the $\mathrm{X} / \mathrm{Y} / \mathrm{Z}$ axis of the machining center is $610 / 560 / 560 \mathrm{~mm}$, the speed of the spindle is 50 $8000 \mathrm{r} / \mathrm{min}$, and the area of the worktable is $400 * 400 \mathrm{~mm}$.

\subsection{Analysis of machining error}

After fixture installation, blank clamping and work piece centering are completed, processing tests are started. Processing procedures must be strictly observed to ensure that the operation process is standardized and reasonable, and to ensure personal and property safety. When processing, it is necessary to observe whether the machining center is working properly, whether there is interference such as tool bumping, and whether the cutting fluid and chips are working properly. It is also necessary to increase or decrease the processing speed properly according to 
different processing stages, so as to improve the processing efficiency and accuracy.

The machined impeller is shown in Figure 3.

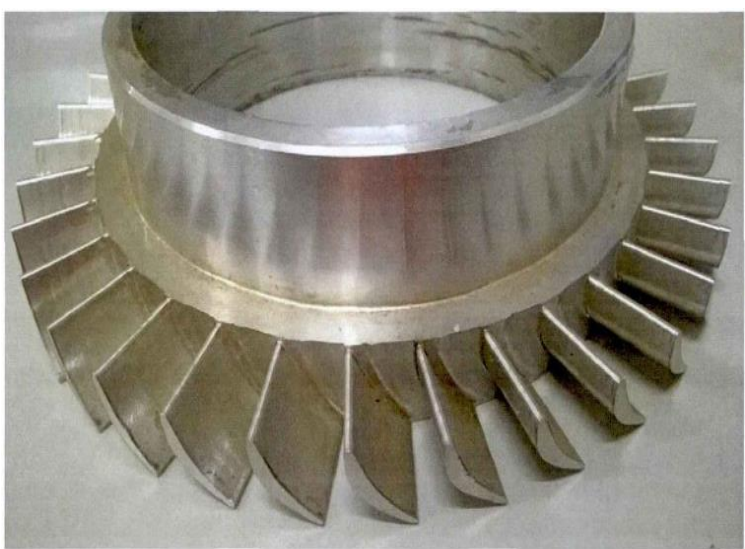

Figure 3: Processing drawings

By observing the processed impeller, it is confirmed that the surface quality of the impeller is better, the surface roughness of the pressure surface and suction surface of the blade is higher, and the precision of the small circle profile at the top and root of the blade is higher, which meets the requirements of the turbo drill for the processing quality.

In order to further satisfy the actual working needs of turbo drill, the blade profile curve of the processed blade is scanned by using the coordinate measuring instrument, as shown in Figure 4.

After obtaining a number of curve data points, the processing error is analyzed by comparing with the design curve contour.

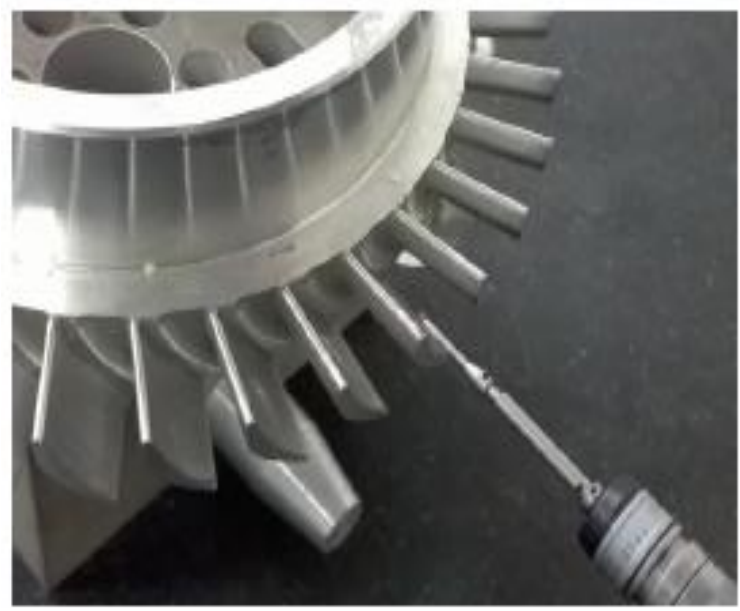

Figure 4: Measure with a coordinate measuring instrument

The data is imported into UG software, and the error analysis of measuring point and theoretical design curve is carried out by using deviation measurement command.
According to the analysis, it can draw the conclusion that the maximum outline error is 0.058 $\mathrm{mm}$, the deviation occurs at the large curvature of blade root, and the processing error of other parts basically meets $0.03 \mathrm{~mm}$.

Therefore, the integrated machining technology of turbo drill impeller can meet the requirements of contour and accuracy.

\section{Conclusion}

The integral forming technology of turbo drill impeller can effectively solve the problem of long production cycle in the process of turbo drill research and development and test, control the cost and complete the turbo drill processing efficiently and quickly, and ensure the processing quality. In addition, the machining center has a strong flexibility, combined with special fixture, only need to modify the processing procedures for different blade shapes. It can save a lot of costs for universities and enterprises, and has the advantages of short manufacturing cycle, flexible processing, high processing efficiency, and has important significance for the research and development of the whole turbo drill.

The main conclusions include the following aspects:

Firstly, the integrated forming technology of turbo drill impeller is put forward, which realizes the processing of turbo drill impeller, and proves that the integrated forming processing impeller has the possibility of manufacturing.

Secondly, UG software is used to build the threedimensional model of impeller, and the processing module is used in the software to formulate the processing technology of impeller, compile the processing program, import the existing NC machining center, and process the impeller as a whole.

Thirdly, through the error analysis of the machined blade profile, it is concluded that the processing method can meet the requirements of processing accuracy and has the ability of actual production.

Fourthly, the integrated forming technology of turbo drill impeller proposed can be applied to the small batch production of turbo drill impeller. In the later stage, the processing program can be optimized to shorten the processing time and improve the processing efficiency.

The impeller produced can be used for bench test, and the better turbo drill design method can be obtained through test. 


\section{References}

[1] Rosa V D S, Taqueda M E S, Paiva J L D, et al, "Nusselt's correlations in agitated tanks using the spiral coil with Rushton turbine and PBT $45^{\circ}$ impeller. Comparison with tanks containing vertical tube baffles", Applied Thermal Engineering, 2017, Volume 110, Pages 13311342.

[2] Kliuev M, Boccadoro M, Perez R, et al, “EDM Drilling and Shaping of Cooling Holes in Inconel 718 Turbine Blades", Procedia Cirp, 2016, Volume 42, Pages 322-327.

[3] Wang H, Ge Y, Lin S, "Technologies in deep and ultra-deep well drilling: Present status, challenges and future trend in the 13 (th) Five-Year Plan period (2016-2020)", Natural Gas Industry, 2017, Volume 4, Issue 5, Pages 319-326.
[4] Uekita M, Takaya Y, "Tool condition monitoring technique for deep-hole drilling of large components based on chatter identification in time-frequency domain", Measurement, 2017, Volume 103, Pages 199-207.

[5] Wang Z, Yin L, "Effects of Impeller Twisting Law on Performance of the ORC Radial Inflow Turbine", Journal of Chinese Society of Power Engineering, 2017, Volume 37, Issue 5, 367-372 and 393.

[6] Doshi A, Channiwala S, Singh P. Inlet impeller rounding in pumps as turbines: An experimental study to investigate the relative effects of blade and shroud rounding. Experimental Thermal \& Fluid Science, 2017, Volume 82, Pages 333-348.

[7] Tao W, Kong F, Xia B, et al, "The method for determining blade inlet angle of special impeller using in turbine mode of centrifugal pump as turbine", Renewable Energy, 2017, Volume 109, Pages 518-528. 